\title{
MODEL HIBRID GENETIC-XGBOOST DAN PRINCIPAL COMPONENT ANALYSIS PADA SEGMENTASI DAN PERAMALAN PASAR
}

\author{
Rimbun Siringoringo ${ }^{\bowtie}$, Resianta Perangin-angin, Jamaluddin \\ Universitas Methodist Indonesia, Medan, Indonesia \\ Email: rimbun.ringo@gmail.com
}

DOI: https://doi.org/10.46880/jmika.Vol5No2.pp97-103

\begin{abstract}
Extreme Gradient Boosting (XGBoost) is a popular boosting algorithm based on decision trees. XGBoost is the best in the boosting group. XGBoost has excellente convergence. On the other hand, XGBoost is a Hyper parameterized model. Determining the value of each parameter is classified as difficult, resulting in the results obtained being trapped in the local optimum situation. Determining the value of each parameter manually, of course, takes a lot of time. In this study, a Genetic Algorithm (GA) is applied to find the optimal value of the $X G B o o s t$ hyperparameter on the market segmentation problem. The evaluation of the model is based on the ROC curve. Test result. The ROC test results for several SVM, Logistic Regression, and Genetic-XGBoost models are 0.89; 0.98; 0.99. The results show that the Genetic-XGBoost model can be applied to market segmentation and forecasting.
\end{abstract}

Keyword: Genetic Algorithm, Market Forecasting, Extreme Gradient Boosting, Market Segmentation, Principal Component Analysis.

\begin{abstract}
ABSTRAK
Extreme Gradient Boosting atau XGBoost adalah algoritma boosting populer yang didasarkan pada pohon keputusan. XGBoost merupakan yang terbaik pada kelompok boostin. XGBoost memiliki konvergensi yang sangat baik. Disisi lain, XGBoost merupakan model yang Hyper parameter. Penentuan nilai setiap parameter tergolong sulit mengakibatkan hasil yang diperoleh terjebak pada situasi local optimum. Penentuan nilai setiap parameter secara manual tentu saja menghabiskan waktu yang tidak sedikit. Pada penelitian ini, Genetic Algoritm (GA) diterapkan untuk pencarian nilai optimal hyperparameter XGBoost pada masalah segmentasi pasar. Evaluasi model didasarkan kurva ROC. Hasil pengujian. Hasil pengujian ROC untuk beberapa model SVM, Logistic Regression, dan Genetic-XGBoost adalah sebesar 0,89; 0,98; 0,99. Hasil penelitian menunjukkan bahwa model Genetic-XGBoost dapat diterapkan pada segmentasi dan peramalan pasar.

Kata Kunci: Algoritma Genetika, Peramalan Pasar, Extreme Gradient Boosting, Segmentasi Pasar, Principal Component Analysis.
\end{abstract}

\section{PENDAHULUAN}

Indonesia menempati urutan pertama dengan jumlah minimarket terbanyak di Asia Tenggara. Berdasarkan data yang di publikasikan pada (Mulya, $\mathrm{Si}$, Hermawan, \& Evienia, 2019), terdapat 43.826 minimarket pada tahun 2019. Terdapat beberapa faktor yang mempengaruhi kondisi tersebut, yaitu pertambahan usia muda kelas menengah (Aribawa, 2016) serta aktivitas masyarakat yang sibuk. Dengan meningkatnya penetrasi internet, masyarakat kini lebih banyak mendapatkan informasi penawaran merek dan produk tertentu. Oleh karena itu diperlukan metode penawaran yang tepat sesuai dengan selera lokal dan perilaku konsumen agar kelangsungan bisnis berjalan dengan lancar.

\section{TINJAUAN PUSTAKA \\ Penelitian Terkait}

Penerapan sains data dan sistem-sistem cerdas dapat membantu segmentasi pasar dan konsumen. Beberapa studi bidang segmentasi pasar melakukan pendekatan pada dua pendekatan utama yaitu pendekatan time series (Anggraeni, Andri, Sumaryanto, \& Mahananto, 2017), dan machine learning (Chatzis, Siakoulis, Petropoulos, Stavroulakis, \& Vlachogiannakis, 2018). Metode time series melibatkan berbagai model diantaranya adalah exponential smooting dan ARIMA (Joyce \& Br, 2020). Hasil penelitian menunjukan bahwa model tersebut dapat memprediksi tren volume sampah. Disisi lain, metode-metode di atas tidak teralu memuaskan 
terutama pada kasus-kasus non linier (H. Wang, Lei, Zhang, Zhou, \& Peng, 2019). Model-model machine learning yang juga populer pada masalah segmentasi adalah artificial neural network (ANN) (Pourdaryaei et al., 2019), support vector regression (SVR) (Li, Wang, Cheng, \& Bai, 2020), dan metode Convolutional Neural Network (CNN). Disisi lain, metode-metode di atas sering terjebak pada optimum lokal dan overfitting (Cai et al., 2020). XGBoost adalah motode machine learning yang sangat populer. Salah satu kelebihan XGBoost adalah tingkat konvergensi dan generalisasi yang sangat baik (Jiang, Tong, Yin, \& Xiong, 2019), (Y. Wang \& Guo, 2020). Penerapan XGBoost pada klasifikasi menghasilkan tingkat akurasi yang tinggi (Wu, Guo, \& Wang, 2020).

Meskipun XGBoost terkenal sebagai model yang robust, banyak studi mengemukakan beberapa kelemahan metode ini. XGBoost merupakan model yang memiliki banyak Parameter (Hyper parameter). Penentuan nilai setiap parameter tergolong sulit mengakibatkan hasil yang diperoleh terjebak pada situasi local optimum (Mai, Sheng, Shi, \& Liao, 2021). Penentuan nilai setiap parameter secara manual tentu saja menghabiskan waktu yang tidak sedikit.

Pendekatan populer yang diterapkan pada penentua nilai parameter XGBoost adalah Grid Search dan Random Search, Bayesian optimization (Y. Xia, Liu, Li, \& Liu, 2017), (Putatunda \& Rama, 2019). Meskipun metode-metode tersebut mudah untuk di implementasikan, namun termasuk comptational expensive (Putatunda \& Rama, 2019). Genetic Algorithm (GA) merupakan solusi penyelesaian masalah optimasi hyper parameter yang sangat populer, diantaranya adalah (X. Xia, Jiang, Zhou, Li, \& Wang, 2018) pada penyelesaian hyper parameter apada aplikasi polusi air, dan penyelesaian feedforward neural networks (Boonthanawat \& Boonyasiriwat, 2021).

Pada penelitian ini, GA diterapkan untuk pencarian nilai optimal hyper parameter XGBoost pada masalah segmentasi pasar.

\section{XGBoost}

XGBoost merupakan adalah algoritma boosting yang didasarkan pada pohon keputusan atau pohon regresi sebagaimana ditampilkan pada gambar 1 (Jiang et al., 2019). Dengan XGBoost, nilai error dapat direduksi dengan efektif dari pohon pertama (feature, Y) ke pohon selanjutnya (feature, $|\mathrm{Y}-\mathrm{Y} 1|$ ).

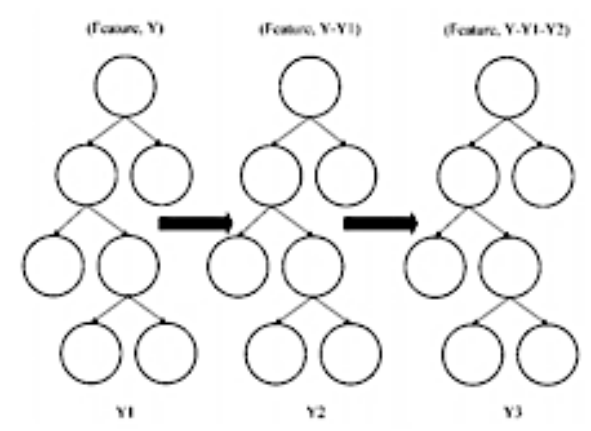

Gambar 1. Pohon Regresi XGBoost

\section{Principal Component Analysis (PCA)}

PCA merupakan metode reduksi fitur data dengan mereduksi variabel-variabel data menjadi lebih kecil. Jika ada data berbentuk matrik $X$ pada persamaan (1) dengan sejumlah $n$ atribut $\times m$ record data (Zhang, Zhang, \& Wu, 2020). Pada persamaan tersebut, $t_{i} \in R^{n}$ adalah nilai vektor dan $m$ adalah banyak verktor yang terbentuk

$$
X=t_{1 P_{1}^{T}+} t_{2 P_{2}^{T}+\cdots+t_{m} P_{m+}^{T}=T P^{T}}
$$

Nilai vektor $X$ merupakan principal component untuk matrik $X$. Jika elemen-elemen minor dihilangkan maka hanya tersisa mejnadi sejumlah a elemen principal yang diterapkan, matrik $X$ dapat dijelaskan dalam bentuk persamaan (2).

$$
X=\sum_{i=1}^{a} t_{i P_{i}^{T}}+\sum_{i=a+1}^{m}
$$

\section{METODOLOGI}

Gambaran umum prosedur dan tahapan penyelesaian masalah segmentasi berbasis GeneticXGBoost digambarkan pada gambar 2. 


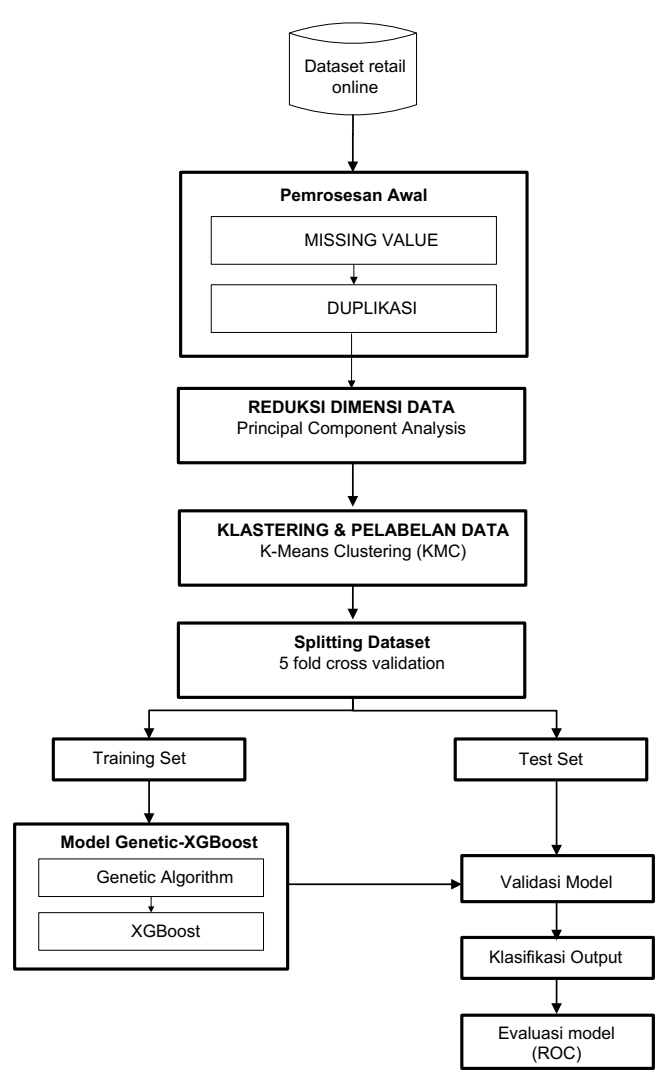

Gambar 2. Model Genetic-XGBoost

Data

Sumber data penelitian ini menggunakan online ritel data dari UCI Machine Learning Dataset (https://archive.ics.uci.edu/ml/datasets/online+retail) Dataset tersebut terdiri dari 525.461 record dan 8 fitur data

Tabel 1. Deskripsi Fitur Dataset

\begin{tabular}{|l|l|l|}
\hline Atribut & Unit & Deskripsi \\
\hline Invoice_No & Nominal & Nomor transaksi \\
\hline Stock_Code & Nominal & Kode produk \\
\hline Description & Nominal & Nama produk \\
\hline Quantity & Numeric & $\begin{array}{l}\text { Banyak produk per } \\
\text { transaksi }\end{array}$ \\
\hline Invoice_Date & Numeric & Tanggal transaksi \\
\hline Unit_Price & Numeric & Harga produk \\
\hline Customer_ID & Nominal & $\begin{array}{l}\text { Nomor unik setiap } \\
\text { pelanggan }\end{array}$ \\
\hline Country & Nominal & Negara pelanggan \\
\hline
\end{tabular}

\section{Pemrosesan awal}

Data awal yang digunakan yaitu online retail dataset terdapat missing value, data outlier dan duplikasi di data. Penanganan ke tiga aspek data ini bertujuan agar akurasi klasifikasi dapat dimaksimalkan. Selanjutnya adalah transformasi data awal menjadi data yang diberi label atau klaster. Model data yang diterapkan untuk penelitian ini sesuai dengan skema pada gambar 3. Fitur data dengan dimensi $m n$ dengan $m$ adalah label atau klaster data, dan $n$ merupakan banyak fitur data. Pelabelan data didasarkan pada hasil klaster menggunakan K-Means Clustering (KMC).

\begin{tabular}{|c|c|c|c|c|}
\hline & fitur 2 & fitur 3 & $\ldots$ & fitur n \\
\hline target 1 & & & $\ldots$ & \\
\hline target 2 & & & $\ldots$ & \\
\hline target 3 & & & $\ldots$ & \\
\hline$\ldots$ & $\ldots$ & $\ldots$ & $\ldots$ & $\ldots$ \\
\hline target $m$ & & & $\ldots$ & \\
\hline
\end{tabular}

Gambar 3. Model Transformasi Data Dimensi $m x n$

\section{Genetic Algorithm (GA) \\ Fungsi fitness}

Fungsi fitness untuk GA ditentukan berdasarkan skor $F 1$ sebagaimana di rumuskan pada persamaan (3).

$$
F 1=\frac{T P}{T P+1 / 2^{(F P+F N)}}
$$

Dengan TP adalah True Positive, FP adalah False Positive, dan FN adalah False Negative. Pengkodean nilai setiap parameter XGBoost ditentukan secara acak uniform adalah sebagai berikut:

Tabel 2. Format Data Parameter XGBoost

\begin{tabular}{|l|l|l|}
\hline No & Parameter & Nilai (min, max), step \\
\hline 1 & Learning Rate & $(0.01,1), 2$ \\
\hline 2 & N Estimators & $(10,1500), 25$ \\
\hline 3 & Max Depth & $(1,10), 1$ \\
\hline 4 & Min Child Weight & $(0.01,10.0), 2$ \\
\hline 5 & Gamma Value & $(0.01,10.0), 2$ \\
\hline 6 & Sub Sample & $(0.01,1.0), 2$ \\
\hline 7 & Col Sample By Tree & $(0.01,1.0), 2$ \\
\hline
\end{tabular}

Skema pengkodean GA membetuk matriks numerik berdimensi $8 \times 8$ yaitu 8 generasi dengan setiap generasi terdiri dari 8 parent.

\section{HASIL DAN PEMBAHASAN \\ Pemrosesan awal}

Dengan metode Inter Quartile Range (IQR), outlier data pada Atribut UnitPrice dan Quantity (gambar 4) direduksi sehingga menyajikan data yang lebih baik sebagaimana disajikan melalui gambar 5 . 


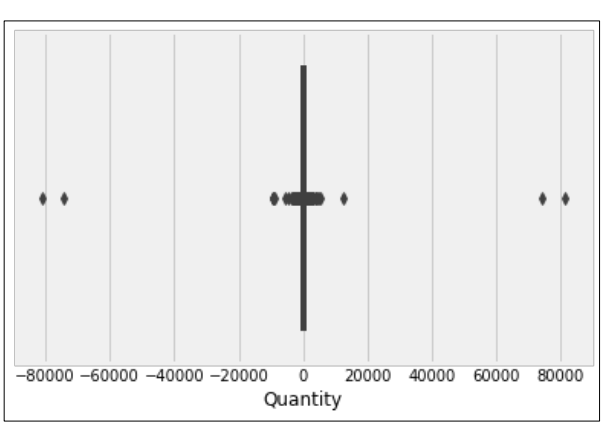

Gambar 4. Visualisasi Boxplot Outlier Data

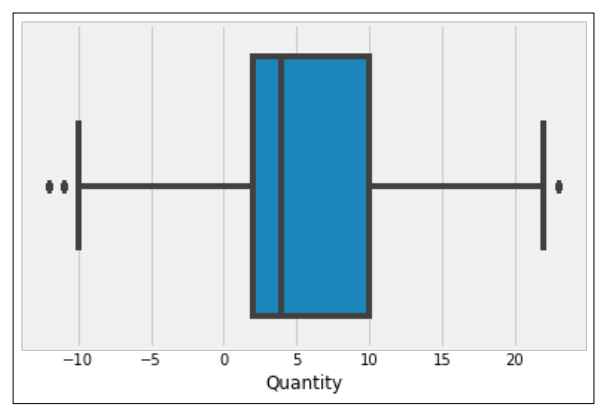

Gambar 5. Boxplot Tanpa Outier

Visualisasi kemunculan setiap keyword sesuai dengan grafik pada gambar 5. Keyword produk pada dataset ada sebanyak 1404 term.

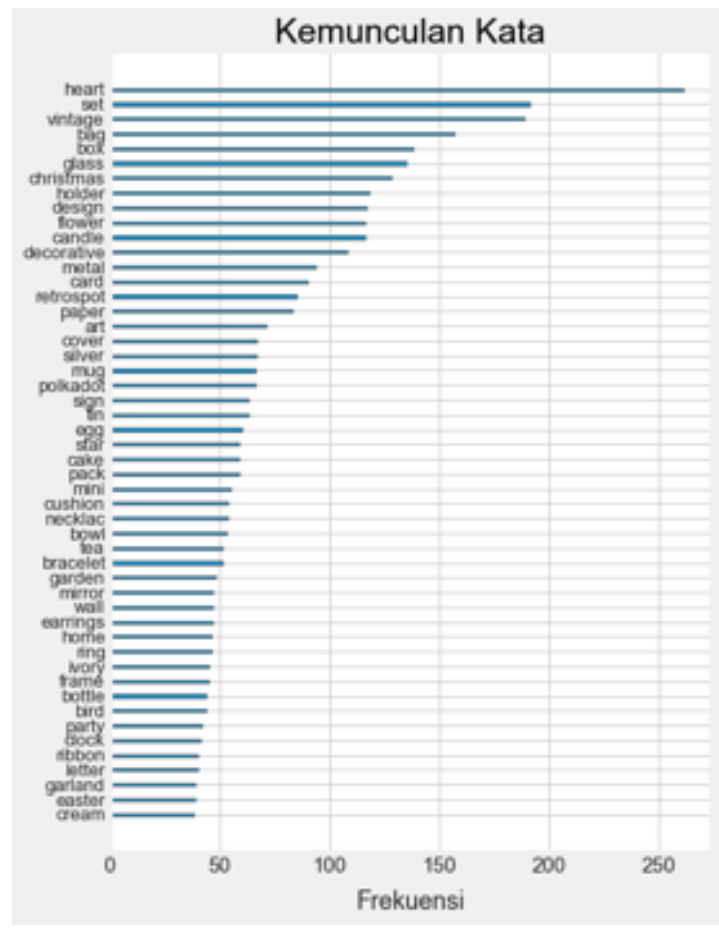

Gambar 6. Frekuensi kemunculan keyword

Penerapan PCA menghasilkan kondisi klaster yang baik yang terbukti dari visualisasi klaster yang terpisah antara klaster yang satu dengan yang lainnya sebagaimana ditampilkan pada gambar 7 .

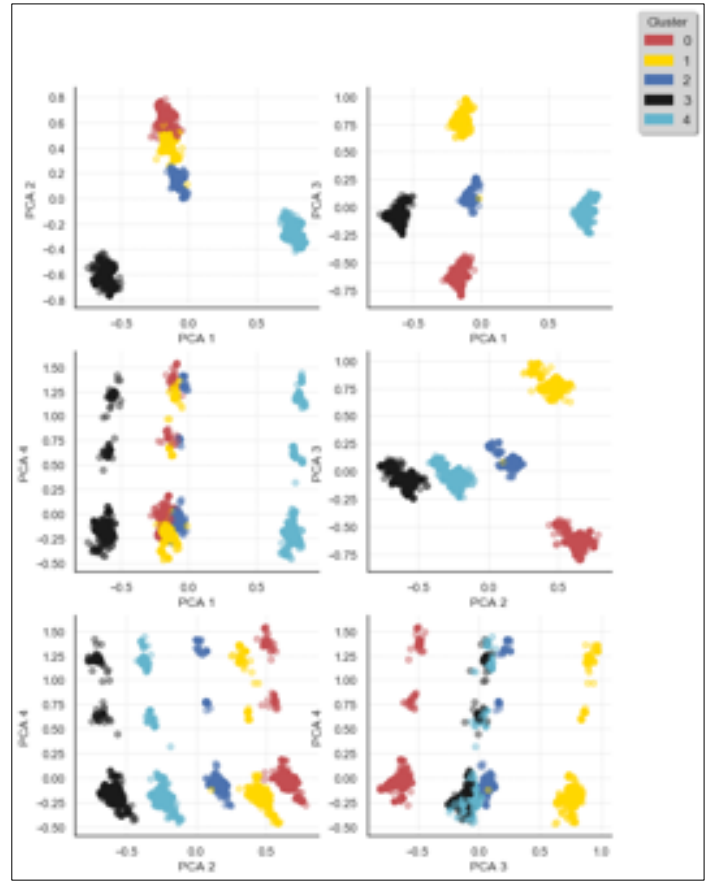

Gambar 7. Visualisasi klaster

Hasil Transformasi dataset ditampilkan pada tabel 3 . Banyak fitur data adalah 5 fitur yaitu $X=\left\{k \_0, k \_1\right.$, k_2, k_3, k_4\} dan banyak target label adalah 11 klaster yaitu $\mathrm{Y}=\{0,1,2,3,4,5,6,7,8,9,10\}$

Tabel 3. Data Hasil Klaster Pelanggan

\begin{tabular}{|r|r|r|r|r|r|r|}
\hline No & \multicolumn{1}{c|}{$\mathbf{k} \_\mathbf{0}$} & \multicolumn{1}{c|}{$\mathbf{k} \_\mathbf{1}$} & \multicolumn{1}{c|}{$\mathbf{k} \_\mathbf{2}$} & \multicolumn{1}{c|}{$\mathbf{k} \_\mathbf{3}$} & \multicolumn{1}{c|}{$\mathbf{k} \_\mathbf{4}$} & cluster \\
\hline $\mathbf{1}$ & -1.782 & -0.076 & 0.058 & -0.226 & -0.243 & 3 \\
\hline $\mathbf{2}$ & 0.652 & 0.988 & -2.501 & -0.416 & -0.605 & 0 \\
\hline $\mathbf{3}$ & -0.550 & 0.527 & 0.902 & -0.734 & 0.708 & 3 \\
\hline $\mathbf{4}$ & -1.445 & 1.457 & -2.071 & 1.138 & -1.771 & 2 \\
\hline $\mathbf{5}$ & 3.706 & -0.280 & 0.165 & -0.936 & -0.376 & 1 \\
\hline $\mathbf{6}$ & -0.187 & 1.208 & 2.139 & -0.592 & -1.132 & 6 \\
\hline $\mathbf{7}$ & -0.008 & -0.073 & -0.645 & 0.149 & -0.362 & 3 \\
\hline $\mathbf{8}$ & 1.404 & -0.213 & -0.256 & -0.513 & -0.340 & 1 \\
\hline $\mathbf{9}$ & 2.701 & 0.630 & 0.762 & 0.197 & 0.020 & 1 \\
\hline $\mathbf{1 0}$ & 2.309 & 0.470 & -0.374 & 0.097 & -0.619 & 1 \\
\hline
\end{tabular}

Tabel 4. Segmentasi Data Produk Dan Konsumen

\begin{tabular}{|c|r|r|r|r|r|r|}
\hline $\begin{array}{c}\text { Klaster } \\
(\mathbf{Y})\end{array}$ & $\mathbf{k} \_\mathbf{0}$ & $\mathbf{k} \_\mathbf{1}$ & $\mathbf{k} \_\mathbf{2}$ & $\mathbf{k} \_\mathbf{3}$ & $\mathbf{k} \_\mathbf{4}$ & $\begin{array}{c}\text { Jlh } \\
\text { konsu } \\
\text { men }\end{array}$ \\
\hline 4 & $\mathbf{5 9 , 6 4 2}$ & 10,137 & 13,483 & 9,576 & 3,600 & 289 \\
\hline 6 & 7,607 & $\mathbf{5 8 , 2 2 0}$ & 10,604 & 14,327 & 3,085 & 351 \\
\hline 3 & 9,458 & 12,801 & $\mathbf{5 6 , 5 3 5}$ & 13,132 & 3,146 & 339 \\
\hline 5 & 4,186 & 9,700 & 5,981 & $\mathbf{6 6 , 9 2 4}$ & 3,484 & 266 \\
\hline 0 & 5,050 & 7,873 & 10,049 & 9,714 & $\mathbf{6 3 , 9 4 2}$ & 48 \\
\hline 10 & 10,581 & 19,333 & 16,134 & $\mathbf{2 3 , 1 7 3}$ & 22,485 & 353 \\
\hline 1 & 11,175 & 23,420 & 20,501 & $\mathbf{2 9 , 7 6 0}$ & 3,620 & 1020 \\
\hline 7 & 11,802 & 24,783 & 20,632 & $\mathbf{2 8 , 2 6 6}$ & 7,061 & 523 \\
\hline 2 & 14,619 & 21,817 & 21,580 & $\mathbf{2 6 , 7 7 5}$ & 8,968 & 76 \\
\hline 9 & 17,949 & 23,625 & 20,197 & 22,942 & 8,706 & 184 \\
\hline 8 & 22,583 & 20,810 & 16,815 & 24,416 & 7,045 & 7 \\
\hline
\end{tabular}


Optimasi Hyperparameter XGBoost dengan GA

Pada gambar berikut di tampilkan proses pencarian nilai parameter XGBoost dengan GA. Pada gambar 8 berikut ditampilkan proses pencarian nilai Parameter colsample_bytree, learning_rate, dan max_depth.

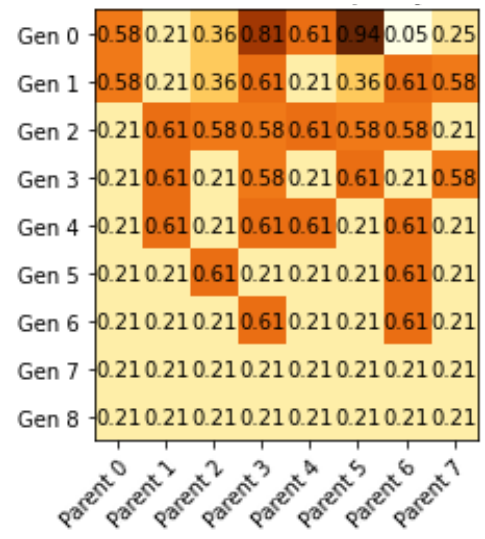

(a)

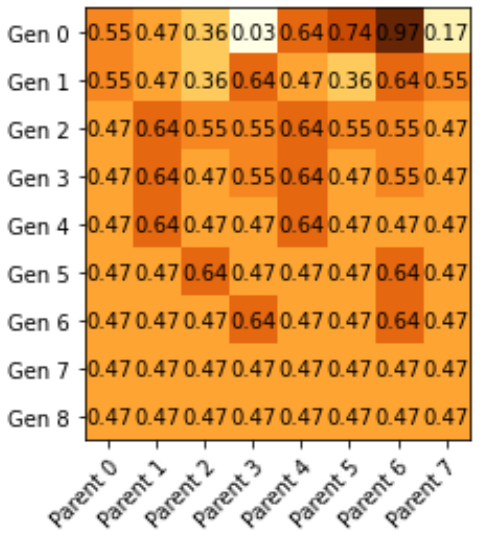

(b)

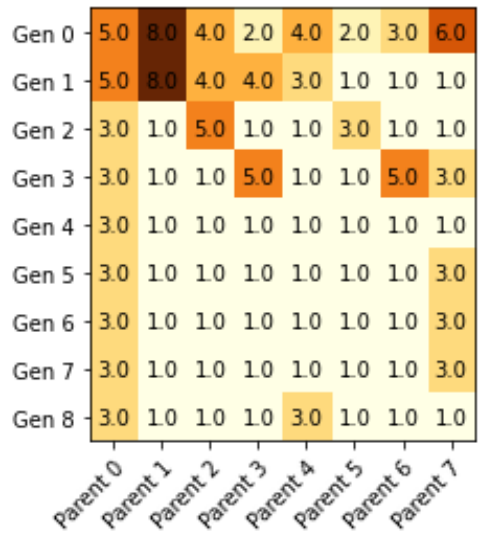

(c)

Gambar 8. Visualisasi pencarian nilai parameter XGBoost dengan GA. (a). Parameter colsample_bytree, (b). Parameter learning_rate, (c). Parameter max_depth
Hasil akhir Parameter XGBoost ditampilkan pada tabel 5 berikut.

Tabel 5. Hyper Parameter XGBoost

\begin{tabular}{|l|c|}
\hline Hyperparameter & Nilai \\
\hline max_depth & 3 \\
\hline min_child_weight & 4,27 \\
\hline gamma & 2,56 \\
\hline learning_rate & 0,47 \\
\hline sub_sample & 0,47 \\
\hline colsample_bytree & 0,21 \\
\hline n_estimator & 79 \\
\hline
\end{tabular}

\section{Evaluasi Model Dengan Grafik ROC}

Hasil perbandingan grafik ROC ditampilkan pada gambar 9 sampai gamabr 11 berikut. ROC model SVM, LogReg, dan Genetic-XGBoost masing-masing 0,$89 ; 0,98 ; 0,99$

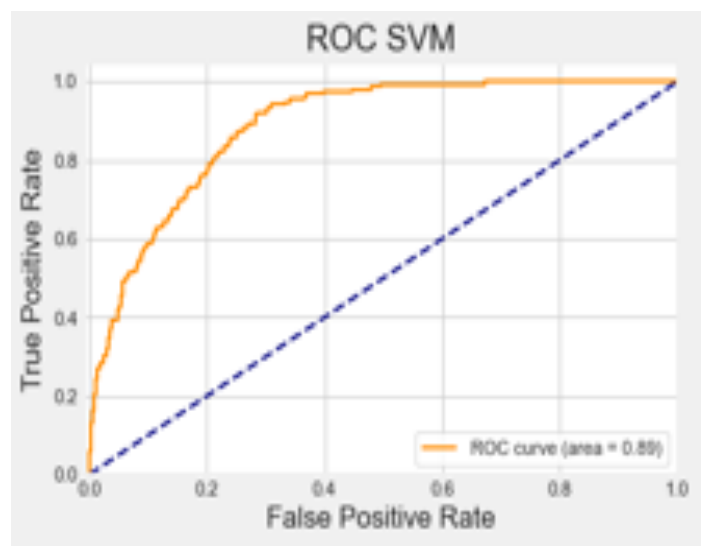

Gambar 9. Grafik ROC SVM

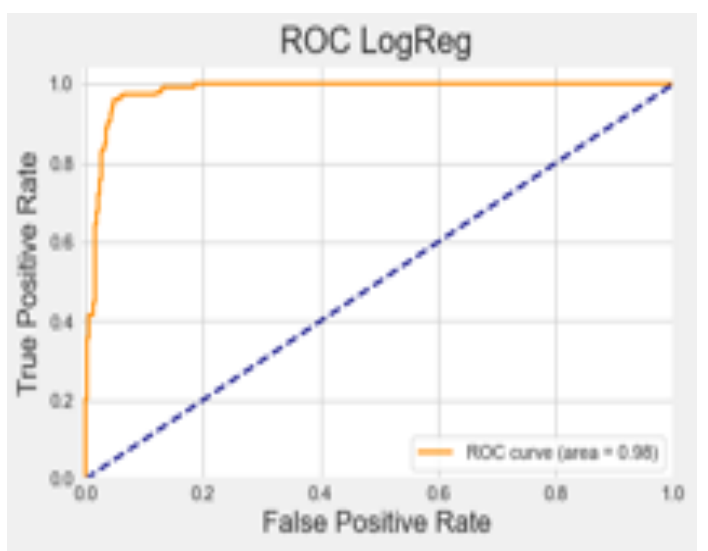

Gambar 10. Grafik ROC LogReg 


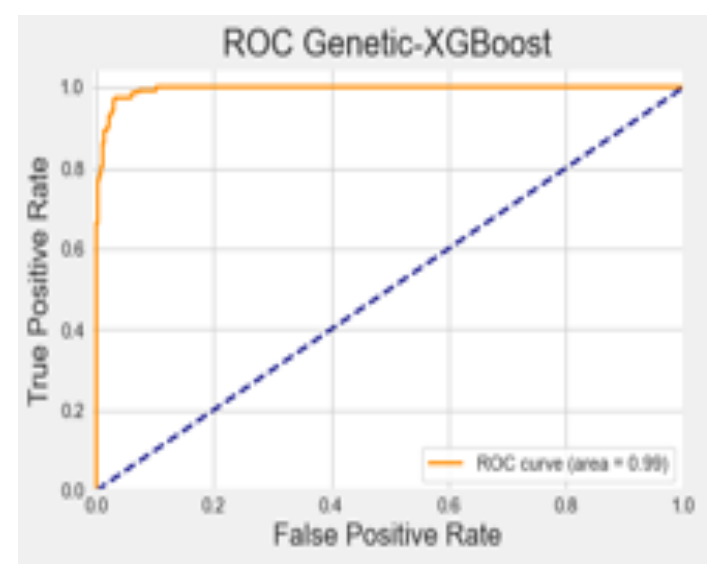

Gambar 11. Grafik ROC Genetic-XGBoost

Berdasarkan grafik ROC tersebut, GeneticXGBoost memiliki nilai ROC yang lebih baik dibanding dua model yang lain.

\section{KESIMPULAN}

Penelitian ini melakukan optimasi hyper parameter XGBoost menggunakan GA dan untuk mereduksi dimensi dataset diterapkan PCA. Berdasarkan hasil penelitian yang telah uraikan pada pembahasan di atas disimpulkan bahwa GA dapat menentukan nilai hyper parmeter XGBoost dengan baik

\section{DAFTAR PUSTAKA}

Anggraeni, W., Andri, K. B., Sumaryanto, \& Mahananto, F. (2017). The Performance of ARIMAX Model and Vector Autoregressive (VAR) Model in Forecasting Strategic Commodity Price in Indonesia. Procedia Computer Science, 124, 189-196. https://doi.org/https://doi.org/10.1016/j.procs.20 17.12 .146

Aribawa, D. (2016). E-commerce strategic business environment analysis in Indonesia. International Journal of Economics and Financial Issues, 6(6Special Issue), 130-134.

Boonthanawat, C., \& Boonyasiriwat, C. (2021). Finding optimal hyperparameters of feedforward neural networks for solving differential equations using a genetic algorithm. Journal of Physics: Conference Series, 1719(1), 12033. https://doi.org/10.1088/17426596/1719/1/012033

Cai, R., Xie, S., Wang, B., Yang, R., Xu, D., \& He, Y. (2020). Wind Speed Forecasting Based on Extreme Gradient Boosting. IEEE Access, 8, 175063-175069. https://doi.org/10.1109/access.2020.3025967

Chatzis, S. P., Siakoulis, V., Petropoulos, A., Stavroulakis, E., \& Vlachogiannakis, N. (2018). Forecasting stock market crisis events using deep and statistical machine learning techniques.
Expert Systems with Applications, 112, 353371.

https://doi.org/https://doi.org/10.1016/j.eswa.20 18.06.032

Jiang, Y., Tong, G., Yin, H., \& Xiong, N. (2019). A Pedestrian Detection Method Based on Genetic Algorithm for Optimize XGBoost Training Parameters. IEEE Access, 7, 118310-118321. https://doi.org/10.1109/access.2019.2936454

Joyce, H. M. V, \& Br, M. (2020). Modeling and Forecasting of COVID-19 Confirmed Cases in Indonesia Using ARIMA and Exponential Smoothing. 198(Issat), 253-258.

Li, C., Wang, X., Cheng, Z., \& Bai, Y. (2020). Forecasting Bus Passenger Flows by Using a Clustering-Based Support Vector Regression Approach. IEEE Access, 8, 19717-19725. https://doi.org/10.1109/ACCESS.2020.2967867

Mai, Y., Sheng, Z., Shi, H., \& Liao, Q. (2021). Using Improved XGBoost Algorithm to Obtain Modified Atmospheric Refractive Index. International Journal of Antennas and Propagation, 2021, 5506599. https://doi.org/10.1155/2021/5506599

Mulya, A. S., Si, M., Hermawan, F., \& Evienia, B. P. (2019). Feasibility analysis of business; Case study in Indonesia minimarket. International Journal of Recent Technology and Engineering, 8(2 Special Issue 4), 790-795. https://doi.org/10.35940/ijrte.B1159.0782S419

Pourdaryaei, A., Mokhlis, H., Illias, H. A., Kaboli, S. H. A., Ahmad, S., \& Ang, S. P. (2019). Hybrid ANN and Artificial Cooperative Search Algorithm to Forecast Short-Term Electricity Price in De-Regulated Electricity Market. IEEE Access, 7, 125369-125386. https://doi.org/10.1109/ACCESS.2019.2938842

Putatunda, S., \& Rama, K. (2019). A Modified Bayesian Optimization based Hyper-Parameter Tuning Approach for Extreme Gradient Boosting. 2019 Fifteenth International Conference on Information Processing (ICINPRO), 1-6.

https://doi.org/10.1109/ICInPro47689.2019.909 2025

Wang, H., Lei, Z., Zhang, X., Zhou, B., \& Peng, J. (2019). A review of deep learning for renewable energy forecasting. Energy Conversion and Management, 198, 111799.

https://doi.org/https://doi.org/10.1016/j.enconma n.2019.111799

Wang, Y., \& Guo, Y. (2020). Forecasting method of stock market volatility in time series data based on mixed model of ARIMA and XGBoost. China Communications, 17(3), 205-221. https://doi.org/10.23919/JCC.2020.03.017

Wu, D., Guo, P., \& Wang, P. (2020). Malware Detection based on Cascading XGBoost and Cost Sensitive. 2020 International Conference on Computer Communication and Network 
Security (CCNS), 201-205.

https://doi.org/10.1109/CCNS50731.2020.00051

Xia, X., Jiang, S., Zhou, N., Li, X., \& Wang, L.

(2018). Genetic algorithm hyper-parameter optimization using Taguchi design for groundwater pollution source identification. Water Supply, 19(1), 137-146.

https://doi.org/10.2166/ws.2018.059

Xia, Y., Liu, C., Li, Y., \& Liu, N. (2017). A boosted decision tree approach using Bayesian hyperparameter optimization for credit scoring. Expert Systems with Applications, 78, 225-241. https://doi.org/https://doi.org/10.1016/j.eswa.20 17.02.017

Zhang, Y., Zhang, B., \& Wu, Z. (2020). Multi-Model Modeling of CFB Boiler Bed Temperature System Based on Principal Component Analysis. IEEE Access, 8, 389-399. https://doi.org/10.1109/ACCESS.2019.2961414 